\title{
Meta-Analysis on the Effect of Physical Therapy Methods on Myofascial Pain Syndrome: The Cases of Domestic Research
}

\author{
Chan Myeong Kim¹, Jae-Kwang Lee ${ }^{2}$ \\ 'Korea Safety Health Environment Foundation, Work Environment Health Center, Cheongju, Republic of Korea; ${ }^{2}$ Department of Physical Therapy, \\ Graduate school, Daegu Catholic University, Daegu, Republic of Korea
}

Purpose: The primary purposes of this study were to identify the degree of the effect size and the variables related to it on the effects of physical therapy on myofascial pain syndrome.

Methods: This study collected 15 studies published between 2008.01.01 and 2019.12.31. The Analysis results confirmed 57 effect size data. The random-effect model was chosen because of the heterogeneity of the data.

Results: First, the full case showed the largest mean effect size of $2.03(p<0.001)$. Second, the size of the effect, according to the handson intervention, was $2.74(p<0.003)$. Third, the VAS showed an effect size of $2.30(p<0.001)$. Fourth, the intervention period showed a 1 - to 15 -day effect size of $2.94(p<0.001)$. The number of interventions showed a 6 to 10 effect size of $2.84(p<0.006)$. The number of participants showed a 10 or less effect size of $2.66(p<0.001)$. Finally, the 'Trim and Fill' result confirmed that the calibration effect size was $0.93(\mathrm{p}<0.001)$.

Conclusion: Physical therapy had a great effect on myofascial pain syndrome in the neck and shoulders, and that the effect differed according to the methods of the intervention and the methods of evaluation.

Keywords: Myofascial pain syndromes, Exercise, Meta-analysis

\section{서 론}

현대 사회는 주로 앉아서 하는 일이 서서 하는 일보다 많아져 하지보 다는 상지에 작업을 집중시킴으로써 근골격계에 피로가 쉽게 유발 되는 통증의 호소가 많아졌다. 근골격계 장애는 취업 연령층에 있는 사람에게 발생되는 기능장애의 주원인이며, 다른 연령층의 사람들 에게도 장애를 일으키는 요인이다. 주로 허리, 목, 어깨 등 만성적인 통증이 적어도 1 주일 이상 뺏뻣함, 따끔거림, 타는듯한 느낌, 찌릿찌 릿함, 무감각 등을 유발하는 것으로, ${ }^{2}$ 만성목통증이 있는 환자와 정 상인을 비교했을 때 만성목통증이 있는 환자에게서 운동감각(Kinesthesia)이 감소된다고 보고되었다. ${ }^{3}$ 이러한 근골격계 질환 중 누구나 일생에서 한번 이상 경험할 수 있는 흔한 통증 질환인 근막통증증후 군은 증상이 없는 성인 여성 인구의 $54 \%$, 남성의 $45 \%$ 에서 잠재성 통 증유발점들이 존재하고, 근골격계 통증을 유발시키는 가장 흔한 원 인으로 알려져 있으며, ${ }^{4}$ 근육의 과사용과 부적절한 자세로 인한 근육 의 손상 등 반복적인 미세외상, 스트레스, 영양 및 대사의 불균형, 감

Received Jul 10, 2020 Revised Jul 27, 2020

Accepted Aug 14, 2020

Corresponding author Jae-Kwang Lee

E-mail dgkora@naver.com
염 등이 촉진 인자로 거론되고 있다. ${ }^{5}$

진단은 근육이나 연부조직에 매우 예민한 통증점과 단순한 소결 절이 있고, 운동범위의 제한, 근약증과 피로감, 압박 시 원위부로의 뻗 치는 통증을 동반하고 단단한 띠가 촉지 되거나 압진이 발통점에 가 해질 때 보여 지는 국소 연축반응, 또는 유발점에 압력을 가하면 환자 가 통증에 의해 펄쩍 뛰는 점프 징후(jump sign)를 보일 때 근막동통 증후군이라 진단할 수 있다. 특히 목, 어깨 상부에 많이 발생하며 머 리나 목에 중요한 신경과 근육이 집중되어 있어 바로 이 부분이 이완 되면 다른 신체 부위는 쉽게 이완될 수 있기 때문에 이 부위의 긴장 이 있는지를 검사하는 것과 치료가 무엇보다 중요하다고 할 수 있다. ${ }^{3}$ 이 질환의 치료목적은 통증을 감소시키고 손상을 당한 근육의 긴장 을 감소시키는데 있고, ${ }^{7}$ 치료방법으로는 침술, 도수치료, 마사지, 지압, 초음파, 열이나 냉의 적용, 경피신경전기자극, 냉각제 분사와 신장 기 법, 건침, 통증점 주사요법 등이 있다. ${ }^{8}$

근막통증 증후군은 재활 전문가인 물리치료사가 많은 연구를 통 해 최선의 치료를 제공하기 위해 노력하고 해결해야 할 중요한 질환 
으로 체계적이고 과학적인 근거 중심의 치료가 이루어져야 한다. 메 타분석은 같은 주제로 시행된 여러 개별연구들을 분석하여 통합하 고자 하는 의도로 이루어지는 연구 방법이다. ${ }^{9}$ 장점으로는 첫째, 일련 의 연구결과들을 통합하는데 있어 체계적이며 정확한 결론을 내릴 수 있고, 둘째, 사용 가능한 자료들의 여러 결점이 지니는 편견을 통제 할 수 있으며, 셋째, 모집단의 평가가 가능하며, 넷째, 복잡한 통계를 사용할 때 연구방법, 연구대상, 범위, 조건 그리고 실험기간 사이의 관 계를 동시에 규명할 수 있다는 점이다. 단점으로는 결과에 초점을 맞 추고 있어 중재변수의 개입이나 상호작용 효과를 무시함으로써 한 연구의 결과를 지나치게 단순화시킬 수도 있다. ${ }^{10}$ 그러함에도 불구하 고 메타분석은 개별연구의 표본을 종합하여 좀 더 큰 표본을 가지고 가설을 검정하기 때문에 통계적 검정력을 높일 수 있으며, 서로 상충 되는 연구결과가 있을 때 그 원인이 어디에 있는지 살펴볼 수 있는 기 회를 주는 등의 장점으로 인하여, 오늘날 의학, 보건학, 간호학, 교육 학 등의 학문영역에서 특히 많이 사용되고 있는 연구방법이다. ${ }^{11}$ 이에 따라 본 연구에서는 메타분석을 통하여 목과 어깨의 근막통증증후 군에 대해 체계적으로 고찰하고 치료 중재와 평가들의 효과를 확인 하여 그와 관련된 변인을 규명하고자 한다.

\section{연구 방법}

\section{1. 연구 설계 및 연구 절차}

본 연구의 연구 대상은 목과 어깨의 근막통증증후군이고 중재방법
은 물리치료 중재이며, 비교집단은 대상 중재와 다른 중재 방법이다. 연구 결과는 시각 통증 척도, 압력 통증 역치이며, 연구 설계 유형은 사전-사후 무작위대조시험 설계방식의 실험 연구로 선정하였다.

\section{2. 자료 선정}

핵심 질문을 근막통증증후군에 대한 물리치료의 관련 변인은 무엇 인가?'로 구성하였으며, 구체적인 선정기준은 다음과 같다. 1) 목과 어 깨의 근막통증증후군 진단을 받은 환자를 대상으로 한 연구, 2) 물리 치료 중재가 제시된 연구, 3) 통계적 수치가 제시되어 있는 연구, 4) 사 전-사후 무작위대조시험 설계방식의 실험연구, 5) 2008년 1월 1 일-2019년 12월 31일로 최근 11년간의 연구. 배제기준은 다음과 같다. 1) 근막통증증후군에 대해 진단, 약물, 주사, 침, 수술을 적용한 연구, 2) 사전-사후 설계방식이 아닌 연구, 3) 통계적 수치가 없는 연구, 4) 전 문(Full text)을 얻을수 없거나 한국어나 영어가 아닌 연구.

문헌 검색과 선정 전 과정은 PRISMA의 체계적 문헌고찰 흐름도에 의거하여 수행하였다. ${ }^{12}$ 한국학술정보(KCI), 학술연구정보(RISS), 국 회도서관, DBpia 총 4 개의 데이터베이스를 사용하였고 검색 주제어 는 '근막 통증' '근막 동통'을 사용하여 총 183 건의 문헌이 검색되었다. 자료선정의 과정은 본 연구자와 물리치료학 분야 전문가에 의해 시 행되었고 검색된 문헌관리는 Mendeley와 Excel을 사용하였다. 원문 의 제목과 초록을 통해 1 차로 확인하고, 이후 선정기준과 제외기준에 따라 원문을 상세히 검토하여 선정하였다(Figure 1).

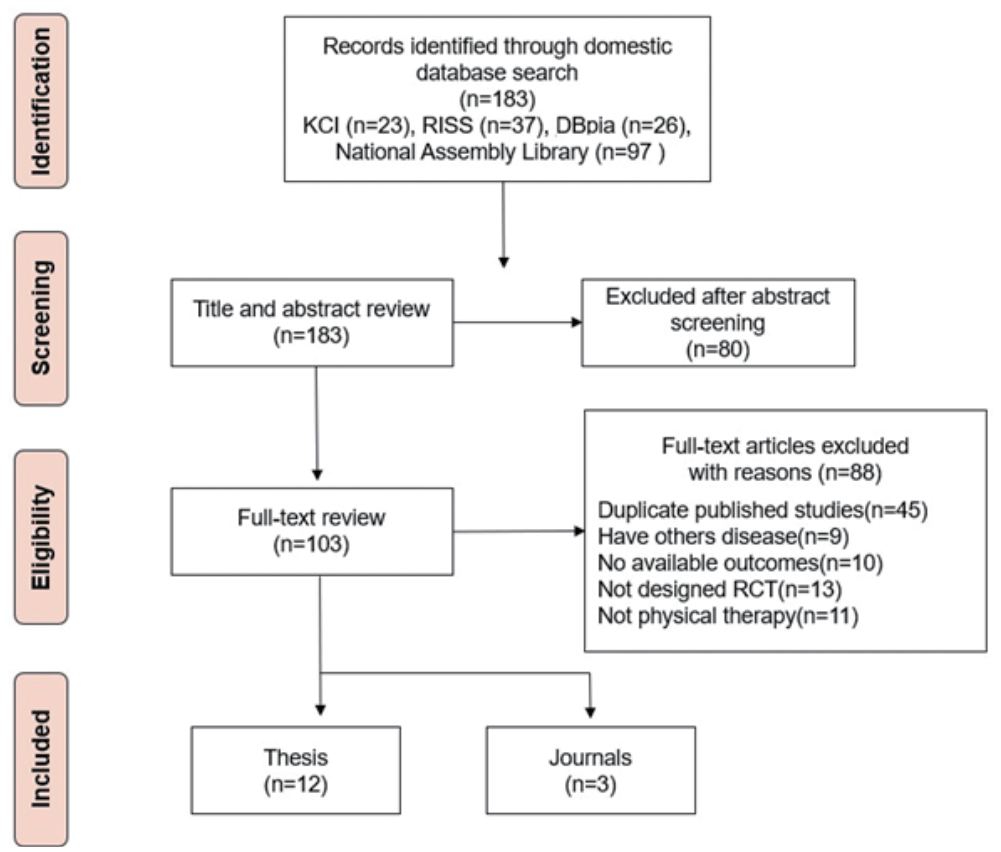

Figure 1. The picture of PRISMA flow chart. 


\section{3. 연구의 비뚤림 위험 평가}

최종 선정된 15 편의 연구에 대해서, 비뚤림 위험 평가를 위해 Cochrane Library에서 개발한 Risk of bias 검증 도구와 Review manager 5.3 프로그램을 이용하였다.

\section{4. 데이터 코딩}

단일집단(사전-사후검사) 메타분석 방법을 사용하였으며, 실험별로 사전, 사후평균, 표준편차 값을 가진 연구만을 선택하였고 수집한 자 료는 연구자명, 치료유형, 중재 방법, 평가 방법, 대상자 수, 치료기간, 치료횟수, 출판연도, 논문명 순으로 엑셀에 입력하여 코딩시트를 구 성하였으며, 코딩 데이터는 R 프로그램에 사용할 수 있도록 csv 파일 형태로 변환하여 분석에 사용하였다. 본 연구의 종속변인 평가들은 사후 효과 값이 정적(양수)과 부적(음수)의 결과를 나타내는 평가들 이 함께 구성되어 있으므로, 음수 결과를 보이는 평가인 시각통증척 도의 경우 사전 평균, 표준편차를 사후 평균, 표준편차의 값과 모두 바꾸어 효과크기가 모두 양수로 제시되도록 계산하여 문제점을 해 결하고 종합적인 결론을 도출하였다.

\section{5. 자료 분석}

\section{1) 통계 처리}

$\mathrm{R}$ 프로그램의 패키지에서 meta와 metafor를 이용하였으며, 각기 다른 개별 연구들의 다른 중재 유형과 비뚤림 위험 다양성이 크다는 것을 인정하기 때문에 무선효과모형을 적용하여 효과크기를 산출하였다. 또한, 변수의 유형에 따라 범주형 변수는 Meta-ANOVA로, 연속형 변 수는 Meta-Regression으로 조절효과 분석을 하였다.

\section{2) 효과크기의 해석}

효과크기는 표준화된 평균 차이로 해석하며, 교정된 효과크기 $\mathrm{g}$ 를 해석하는 방식은 Cohen's의 d해석과 같다.12

$$
\begin{aligned}
& \text { 작은 효과크기: } \mathrm{ES}_{\mathrm{sm}} \leq 0.20 \\
& \text { 중간효과크기: } 0.20<\mathrm{ES}_{\mathrm{sm}}<0.80 \\
& \text { 큰 효과크기: } \mathrm{ES}_{\mathrm{sm}} \geq 0.80
\end{aligned}
$$

\section{3) 이질성 검증}

효과 크기 간의 차이를 효과 크기의 이질성이라 한다. 연구 간의 효과 크기의 동일성을 검증할 때 사용되는 것이 $\mathrm{Q}$ 와 $\mathrm{df}$ 값이며, 이질성의 비율은 $\mathrm{I}^{2}$ 으로 나타내고 $\mathrm{I}^{2}$ 통계치는 전체 분산에 대한 실제 연구 간 분산의 비율을 나타내며, 개별적인 연구들에서 산출된 효과크기들 의 이질성 정도를 나타낸다. ${ }^{13}$

$I^{2}$ 는 총 분산(전체 관찰 분산)에 대한 실제(연구 간) 분산의 비율을 나타내고, 일반적으로 $\mathrm{I}^{2}$ 가 $25 \%$ 이면 작은 정도의 이질성으로, $50 \%$ 이
면 중간 정도의 이질성으로, $75 \%$ 이상이면 이질성이 매우 큰 것으로 해석한다. ${ }^{13}$

\section{결 과}

본 연구의 전체효과크기는 큰 효과크기로 통계적으로 유의하게 나 타났으며 $(\mathrm{p}<0.001), \mathrm{I}^{2}$ 값이 $91.2 \%$ 로 $75 \%$ 이상이므로 이질성은 크다고 할 수 있다(Figure 2). 중재유형에 따른 분석 결과 손을 사용하는 도수 기법인 Hands on이 높게 나타났고, $95 \%$ 신뢰구간에서도 모두 통계적 으로 유의하게 나타났으며(p<0.003), Hands on, off의 각 중재별 효과 크기는 다음과 같다(Figure 2).

평가방법에 따른 사례 수와 효과크기는 시각통증척도에서 높게 나타났으며, 통계적으로 유의하게 나타났다( $\mathrm{p}<0.001)$ (Figure 2). 치료 대상자 수에 따른 사례 수는 11-20명, 효과크기는 10 명 이하에서 높게 나타났으며, 통계적으로 유의한 것으로 나타났다 $(\mathrm{p}<0.001)$. 치료기 간에 따른 사례 수는 16-30일, 효과크기는 1-15일에서 높게 나타났으 며, 통계적으로 유의한 것으로 나타났다 $(\mathrm{p}<0.001)$. 치료적용 횟수에 따른 사례 수와 효과크기는 6-10회에서 높게 나타났으며, 통계적으로 유의한 것으로 나타났다 $(\mathrm{p}<0.006)$ (Table 1$)$.

출간오류에 대한 분석을 위해 'Trim and Fill'을 이용하여, ${ }^{14}$ 비대칭 을 대칭으로 교정한 결과 23 개의 사례가 추가되어 80 개의 사례로 보 정된 효과크기는 $\mathrm{ES}=0.93$ 이며, 통계적으로 유의하게 나타났다 $(\mathrm{p}<0.001)$ (Table 2, Figure 3).

\section{고 찰}

본 연구에서는 목과 어깨의 근막통증증후군에 대해서 물리치료를 적용한 국내연구들을 모아서 통증개선에 어떠한 효과가 있는지 어떠 한 치료유형이 더 효과적인지를 체계적이고 종합적인 방법인 메타분 석을 통하여 알아보았다. 본 연구에서의 전체효과크기는 $\mathrm{ES}=2.03$ 이 고, 출간오류를 교정한 결과에서도 $\mathrm{ES}=0.93$ 의 효과크기를 보여 물리 치료는 목과 어깨의 근막통증증후군에 큰 효과가 있다는 것을 의미 한다. 선행연구에서도 같은 질환을 가진 아마추어 축구 선수들을 대 상으로 그라스톤 기법, 부황, 허혈성 압박 치료 기법을 적용한 연구에 서 통증감소 효과를 보였고, ${ }^{15}$ 온열치료, 초음파치료, 경피신경자극치 료 후에 충격파치료, 안정화 운동, 테이핑을 각각 적용한 연구에서도 통증감소 효과를 보고하였다.

중재유형을 살펴본 결과 치료사의 손을 사용하지 않는 Hands off 사례가 많았고, 효과크기는 Hands on 치료법이 더 큰 효과크기를 보 였다. Hands on은 치료사가 손을 사용하는 치료기법들로 도수 자극 으로 골지힘줄기관(Golgi tendon organ)에 장력이 발생되어 일정 문턱 


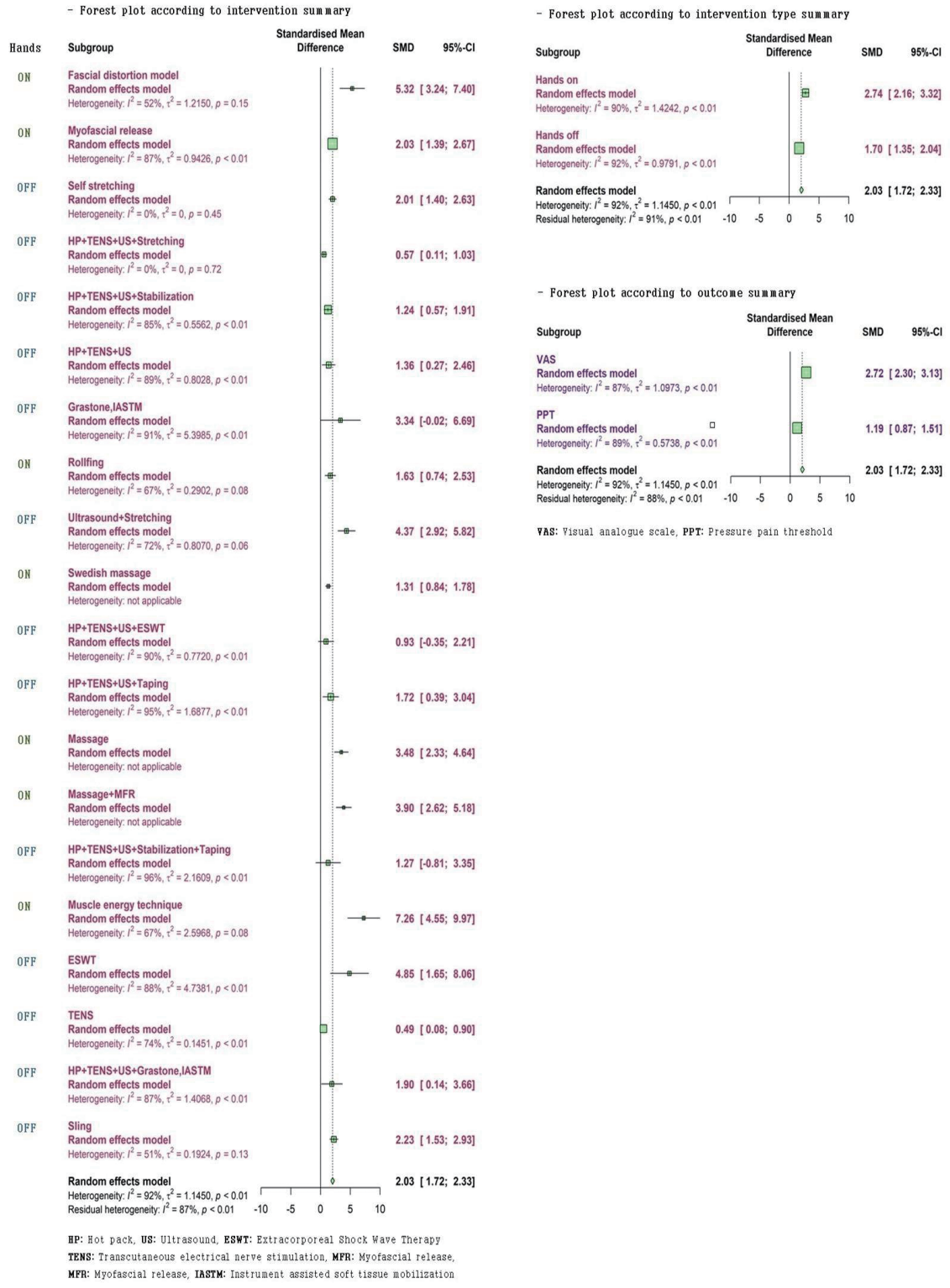

Figure 2. The picture of forest plot according to intervention and outcome.

Table 1. Size of the intervention effect according to the control variable

\begin{tabular}{|c|c|c|c|c|c|c|c|}
\hline \multirow{2}{*}{ Control variable } & \multirow{2}{*}{$N$} & \multirow{2}{*}{ k } & \multirow{2}{*}{ ES (g) } & \multicolumn{2}{|c|}{$95 \% \mathrm{Cl}$} & \multirow{2}{*}{$\mathrm{Q}(\mathrm{df})$} & \multirow{2}{*}{$\mathrm{p}$} \\
\hline & & & & $\mathrm{LL}$ & UL & & \\
\hline \multirow[t]{3}{*}{ No of participants } & $\leq 10$ & 22 & 2.66 & 2.05 & 3.28 & $23.64(2)$ & $<0.001$ \\
\hline & 11 to 20 & 31 & 1.82 & 1.43 & 2.21 & & \\
\hline & $\geq 21$ & 4 & 1.06 & 0.74 & 1.38 & & \\
\hline \multirow[t]{4}{*}{ Intervention period (d) } & 1 to 15 & 5 & 2.94 & 1.99 & 3.90 & $12.55(3)$ & $<0.006$ \\
\hline & 16 to 30 & 42 & 2.12 & 1.75 & 2.49 & & \\
\hline & 31 to 45 & 4 & 1.08 & 0.37 & 1.80 & & \\
\hline & 46 to 60 & 6 & 1.39 & 0.60 & 2.18 & & \\
\hline \multirow[t]{4}{*}{ No of Intervention } & 1 to 5 & 2 & 1.29 & 0.96 & 1.61 & 23.86(3) & $<0.001$ \\
\hline & 6 to 10 & 28 & 2.84 & 2.27 & 3.41 & & \\
\hline & 11 to 15 & 23 & 1.45 & 1.09 & 1.82 & & \\
\hline & $\geq 16$ & 4 & 1.08 & 0.37 & 1.80 & & \\
\hline
\end{tabular}

k: Number of effect size, ES: Effect size. 95\% Cl: 95\% Confidence interval, LL: Lower limit, UL: Upper limit, R: Between-study variability. 

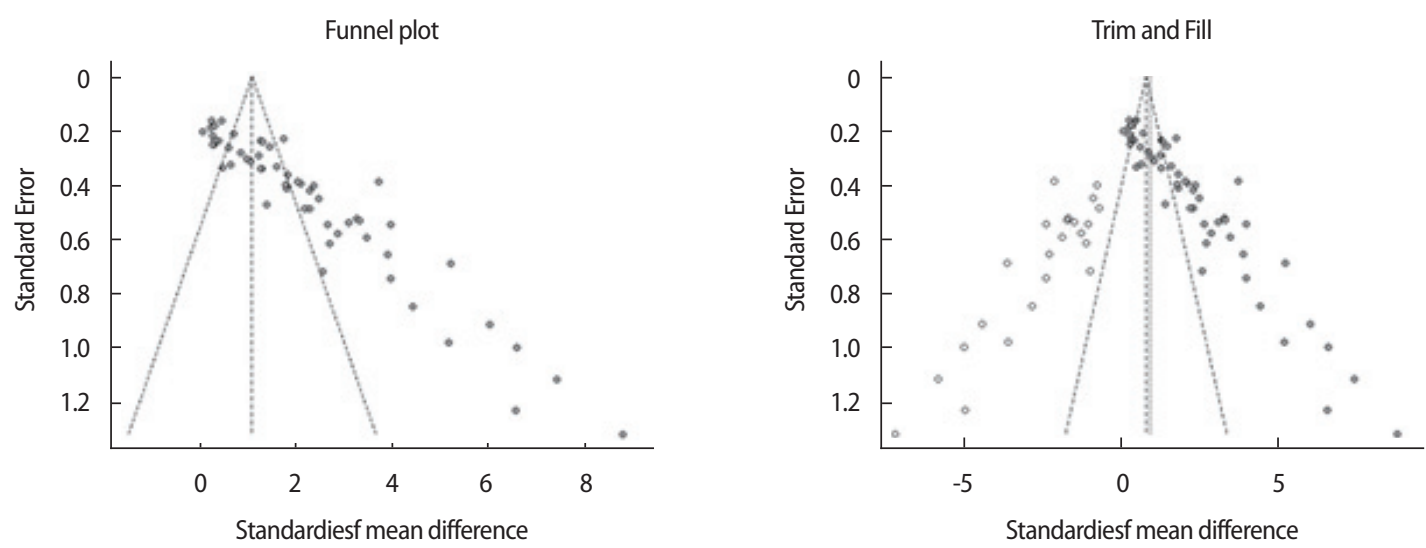

Figure 3. The picture of Funnel plot and Trim and Fill.

Table 2. Trim and Fill results

\begin{tabular}{lccccccc}
\hline $\begin{array}{l}\text { Publication } \\
\text { bias }\end{array}$ & $k$ & $\mathrm{ES}(\mathrm{g})$ & \multicolumn{2}{c}{$95 \% \mathrm{Cl}$} & $\mathrm{Q}(\mathrm{df})$ & $\mathrm{p}$ \\
\cline { 4 - 5 } & & & $\mathrm{LL}$ & $\mathrm{UL}$ & & \\
\hline Trim and Fill & 80 & 0.93 & 0.6 & 1.26 & $1,264.31(79)$ & $<0.001$ \\
\hline
\end{tabular}

값 수준을 넘어서게 되면서 활성화되어 고위 중추로 자극이 전달되 게 되고, 이러한 과정을 거치면 반사적으로 주동근과 협력근의 운동 뉴런을 억제시켜 이완이 발생되며 길항근의 운동뉴런을 흥분시켜 수축시키는 역신장반사(inverse myostatic reflex)를 일으킨다고 하였 다. ${ }^{16,17}$ 골지힘줄기관에서 발생되는 역신장 반사에 의해 일차적으로 근막의 수축은 감소하게 되며, 그에 따라 대사산물은 감소될 수 있으 며 이러한 대사산물의 감소에 대한 결과로 통증 감각의 구심성 섬유 에 대한 흥분도 감소되게 되고, 이는 근막 이완을 촉진하여 혈액이나 림프의 흐름과 여러 조직에 영양소나 산소의 공급을 원활하게 하며, 노폐물들을 조직에서 혈관으로 배출시켜 조직의 영양상태를 개선하 고, 주변 조직을 활성화시켜 통증을 감소시킨다. ${ }^{16,17} \mathrm{Lee}^{18}$ 는 근막변형 모델 치료법이 몸통의 근막에 수분을 분산시키고 수축과 이완 능력 을 향상시킨다고 보고하였고, 이러한 생리적 기전과 선행연구들의 결 과를 보아 본 연구의 Hands on 치료에 높은 효과와 관계되는 것으로 보인다. 또한 Hands on 중재방법들은 근육에 압력을 전달함으로써, 일정한 간격으로 간헐적인 근 수축을 유도하여 혈류가 감소된 근육 내에 순환 혈류량을 증가시켜 산소와 영양소를 공급하여 긴장도를 낮춰 통증을 감소시키고. 교감신경 억제 등의 효과와 가동범위 증가 를 기대할 수 있다. ${ }^{19} \mathrm{Hands}$ off 중재방법은 도수치료기법이 아닌 치료 법으로 목빗근의 근막통증에 키네시오 테이핑을 적용한 연구에서 통증완화와 근육의 기능회복에 긍정적인 효과가 있음을 확인하였 고, ${ }^{20}$ 본 연구에서는 분석한 Hands on, off 중재 각각의 효과크기 결과 를 모두 기술하였다(Figure 2).

평가방법에서는 시각통증척도가 사례 수와 효과크기가 높게 나 타났다. 시각통증척도는 간단하고, 통증정도의 표현에 있어 높은 타
당도를 보이며, ${ }^{21}$ 측정자 내 신뢰도 $(r=0.99)$ 와 측정자 간 신뢰도 $(\mathrm{r}=1.00)$ 가 매우 높은 것으로, ${ }^{22} \mathrm{Lee}$ 등 ${ }^{1}$ 의 안정화 운동, 체외충격파, 테 이핑이 상승모근 근막통증 증후군에 미치는 효과 비교 연구에서 시 각통증척도에 모두 유의한 결과가 보고되었다. 또한 통증평가에 많 이 사용되는 압력통각계는 주관적인 느낌인 통증의 정도를 객관화 시킬 수 있는 기기로 평가자 간 신뢰도는 $r=0.79-0.90$ 이었다.23 조절변 인에서 치료대상자에 대한 사례 수는 11-20명 이하가 가장 많았고 효 과크기는 10 명이하로 대상자 수가 적을수록 효과크기가 높게 나타 났다. 이 결과를 보아 신뢰도의 보완을 위해 더 많은 대상자에 대한 연구가 이루어 져야 할 것이다. 치료 기간의 경우 주로 16 30일 미만 의 치료가 많이 이루어 졌음을 알 수 있고, 효과크기는 1-15일에서 높 게 나타났으며, 치료 횟수의 경우 6-10회, 11-15회가 주를 이루었으며, 효과크기 또한 6-10회가 높게 나타나고 통계적으로도 유의하게 나타 났다. 선행 연구에서도 단기간의 운동중재를 통해서도 통증감소와 신체기능 향상이 있는 것으로 확인된 바 있다. ${ }^{24}$ 하지만 추후 연구에 서는 더 장기적인 관점에서 치료의 효과를 확인할 필요가 있다.

본 연구의 메타분석 결과가 타당한지를 검증하기 위해 비대칭을 대칭으로 교정하고 분석한 결과 출간 오류에 의해 보고되지 않았다 고 가정한 23 개의 사례를 추가했을 때 보정된 효과크기는 $\mathrm{ES}=0.93$ 이 며, $95 \% \mathrm{CI}$ 신뢰구간이 0.60-1.26으로 통계적으로 유의한 결과를 보아 물리치료는 목과 어깨의 근막통증증후군에 큰 효과가 있다는 것을 확인할 수 있었고, Hands on 중재법과 시각통증척도 평가방법에서 큰 효과크기를 나타내는 것을 알 수 있었다. 또한, 대상자수, 치료기 간, 치료횟수의 조절 변인에 의해 영향을 받는 것을 알 수 있었다. 따 라서 본 연구 결과는 목과 어깨의 근막통증증후군에 대한 물리치료 를 더욱 효과적으로 적용하기 위한 자료를 메타분석을 통해 체계적 이고 객관적으로 제시한 연구라고 할 수 있다.

하지만 본 연구에서 고려해야할 한계로는 첫째, 문헌 선정검토를 전문가와 함께 선정하였고 출간오류를 최소화하기 위해 Trim and fill 
을 활용한 보정결과를 제시하였음에도 메타분석이 가진 한계인 출 간오류를 완벽히 해소했다고 할 수는 없을 것이다. 둘째, 국내연구들 을 대상으로 한 연구이므로 결과를 일반화할 수는 없을 것이다. 따라 서, 향후 연구에서는 연구 범위를 넓혀 해외 연구를 포함한 메타분석 이 이루어져야할 것이다.

\section{REFERENCES}

1. Lee JH, Hwang KY, Park YH. Comparing the effects of stability exercise, ESWT, and taping for patients with myofascial pain syndrome of upper trapezius. J Korean Phys Ther. 2012;24(2):82-9.

2. Trinkoff AM, Lipscomb JA, Geiger-Brown J et al. Musculoskeletal problems of the neck, shoulder, and back and functional consequences in nurses. Am J Ind Med. 2002;41(3):170-8.

3. Revel M, Andre-Deshays C, Minguet M. Cervicocephalic kinesthetic sensibility in patients with cervical pain. Arch Phys Med Rehabil. 1991;72(5):288-91.

4. Sola AE, Rodenberger ML, Gettys BB. Incidence of hypersensitive areas in posterior shoulder muscles. A survey of two hundred young adults. Am J Phys Med Rehabil. 1955;34(6):585-90.

5. Lee JH, Kang DH, Kang JI. The effects of myofascial relaxation on blood flow velocity of the cranial artery and pain level in cervicogenic headache patients. J Kor Phys Ther. 2010;22(5):49-56.

6. Sciotti VM, Mittak VL, DiMarco L et al. Clinical precision of myofascial trigger point location in the trapezius muscle. Pain. 2001;93(3):259-66.

7. Hsueh TC, Cheng PT, Kuan TS et al. The immediate effectiveness of electrical nerve stimulation and electrical muscle stimulation on myofascial trigger points1. Am J Phys Med Rehabil. 1997;76(6):471-6.

8. Alvarez DJ, Rockwell PG. Trigger points: diagnosis and management. Am Fam Physician. 2002;65(4):653.

9. Glass G V. Primary, secondary, and meta-analysis of research. Educ Res. 1976;5(10):3-8.

10. Jackson GB. Methods for integrative reviews. Rev Educ Res. 1980; 50(3):438-60.

11. Lee HJ, Oh HH, Choi KH. Meta analysis on the effect of reading development program on reading comprehension. KDISS. 2012;23(3):447-
55.

12. Cohn J. Statistical power analysis for the behavioral sciences. Hillsdale, Lawrence Earlbam Assoc Hillsdale, 1988:25-6.

13. Higgins JP, Green S. Cochrane Handbook for Systematic Reviews of Interventions Version 5.1. 0. Chichester, John Wiley \& Sons Ltd, 2011:27688.

14. Duval S, Tweedie R. Trim and fill: a simple funnel-plot-based method of testing and adjusting for publication bias in meta-analysis. Biometrics. 2000;56(2):455-63.

15. Fousekis K, Kounavi E, Doriadis S et al. The Effectiveness of Instrumentassisted Soft Tissue Mobilization Technique (ErgonŠ Technique), Cupping and Ischaemic Pressure Techniques in the Treatment of Amateur Athletes' Myofascial Trigger Points. J Nov Physiother S. 2016;3:2-7.

16. Kim JM. Neuroanatomy and neurophysiology for physical therapist and occupational therapist. Seoul, Jungdammedia, 2009:77-88.

17. Kim MK, Lee WJ. Effect of fascial distortion model on the pain and movement of neck patient. J Korean Phys Ther. 2019;31(1):24-30.

18. Lee WJ. Effect of Fascial Distortion Model on the Cobb's Angle in Adolescents with Idiopathic Scoliosis. J Korean Phys Ther. 2019;31(1):31-4.

19. Fryer G. Muscle energy technique: An evidence-informed approach. Int J Osteopath Med. 2011;14(1):3-9.

20. Park Y, Bae Y. Change of pain and breathing function following kinesio taping of myofascial pain in sternocleidomastoid muscle. J Korean Phys Ther. 2014;26(5):302-7.

21. Wilkie D, Lovejoy N, Dodd M et al. Cancer pain intensity measurement: concurrent validity of three tools-finger dynamometer, pain intensity number scale, visual analogue scale. Hosp J. 1990;6(1):1-13.

22. Wagner DR, Tatsugawa K, Parker D et al. Reliability and utility of a visual analog scale for the assessment of acute mountain sickness. High Alt Med Biol. 2007;8(1):27-31.

23. Walton D, MacDermid J, Nielson W et al. Reliability, standard error, and minimum detectable change of clinical pressure pain threshold testing in people with and without acute neck pain. J Orthop Sport Phys Ther. 2011;41(9):644-50.

24. Li Y, Su Y, Chen S et al. The effects of resistance exercise in patients with knee osteoarthritis: a systematic review and meta-analysis. Clin Rehabil. 2016;30(10):947-59. 